OPEN ACCESS

Edited by:

Peng Zhou,

Tsinghua University, China

Reviewed by:

Matthew Wagers,

University of California Santa Cruz,

United States

Alan Hezao Ke,

Michigan State University,

United States

*Correspondence:

Zhiyin Dong

rdong@udel.edu

Specialty section:

This article was submitted to

Language Sciences,

a section of the journal

Frontiers in Communication

Received: 07 January 2021

Accepted: 06 April 2021

Published: 20 May 2021

Citation:

Dong Z, Rhodes $R$ and Hestvik A (2021) Active Gap Filling and Island Constraint in Processing the Mandarin

"Gap-Type" Topic Structure.

Front. Commun. 6:650659.

doi: 10.3389/fcomm.2021.650659

\section{Active Gap Filling and Island Constraint in Processing the Mandarin "Gap-Type" Topic Structure}

Zhiyin Dong ${ }^{1 *}$, Ryan Rhodes ${ }^{2}$ and Arild Hestvik ${ }^{1}$

${ }^{1}$ Department of Languages, Literatures and Cultures, University of Delaware, Newark, Delaware, ${ }^{2}$ Rutgers University Center for Cognitive Science, Piscataway, NJ, United States

There is a long-standing debate concerning whether Mandarin topic constructions are movement-derived and form a filler-gap dependency like the English-type topicalization. This ERP study explores this issue by testing whether island constraints, a diagnostic for movement, are actively observed during online processing of the Mandarin "gap-type" topic construction, an understudied area in Mandarin sentence processing research. Following the paradigm of Traxler and Pickering's 1996 study, we manipulated islandhood (relative clause island conditions vs. no island conditions) and plausibility, or whether the topic is a plausible object of the potential subcategorizing verb based on animacy fit (i.e., "greet a teacher" vs. "greet a file") in a $2 \times 2$ design. We predict that any plausibility effect obtained for the non-island conditions would disappear for the island conditions if the parser observes the island constraint and avoids positing gaps inside an island. we observed a P600-previously found for animacy violations-for the non-island conditions but not for the island conditions. Additionally, we found a positive-going component occurring from 588 to $792 \mathrm{~ms}$ at the fronto-central site for the island condition at the potential gap site. While this novel ERP's interpretation is yet to be determined, it is unlikely to indicate any plausibility effect. Our findings suggest that the parser is sensitive to island constraints in online processing of the Mandarin "gap-type" topic structure, and lend support to the movement analysis for Mandarin topicalization.

Keywords: sentence processing, Mandarin topicalization, island constraint, ERP, filler-gap dependencies, active gap filling

\section{INTRODUCTION}

Mandarin Chinese, like many East Asian languages, is considered a "topic prominent" language (e.g., Li and Thompson, 1981). The theme of the construction is often introduced first (the "topic"), followed by the subject and additional information about the theme (the "comment"), as illustrated in
(1) shu wo yijin mai le
The book I already buy Asp ${ }^{1}$
'I have bought (the) book(s).'

This sentence may appear to have a surface structure identical to English-like topicalized

\footnotetext{
${ }^{1}$ Asp is aspect marker.
} 
constructions such as "Vegetables, he won't eat," but it is unclear whether the relationship between the Mandarin topicalized phrase and its thematic position (where it is interpreted) is the same as English (e.g., Huang et al., 2009). English-like topicalization, which is allowed in many languages, is widely accepted to involve a movement-derived filler-gap dependency between the fronted element (the topic or the "filler") and its originating position (after the subcategorizing verb or the "gap") (e.g., Chomsky, 1986; Felser et al., 2003). Both online processing and offline judgment evidence consistently show that the formation of such a dependency is sensitive to island constraints, a signature feature of syntactic movement (e.g., Chomsky, 1986; Traxler and Pickering, 1996). The same, however, cannot be said for Mandarin topic structures. Judgment tasks testing whether topic structures observe island constraints have repeatedly yielded contradictory findings (e.g., Li, 1976; Xu and Langendoen, 1985; Shyu, 1995; Huang et al., 2009), prompting some scholars to argue that topic structures in Mandarin are not movement-derived (e.g., Li and Thompson, 1981; Ts'ao and Cao, 1990; Ning, 1993). Online parsing evidence could be used to clarify this controversy, as it has been widely used to examine the nature of various syntactic dependencies (e.g., Felser et al., 2003; Ben-Shachar et al., 2004). However, existing data on the processing of Mandarin topicalization is very limited. The aim of this paper is two-fold. First, we attempt to establish a more complete real-time parsing profile for this understudied Mandarin structure. Second and more importantly, we seek to test whether a type of island constraint, namely the complex noun phrase constraint, is actively observed in the online processing of a common type of Chinese topic structure (the gap-type topic-comment, see below for more details). This allows us to shed light on whether the Mandarin topic structure forms the same movement-derived filler-gap dependency as English topicalization. To that end we measure ERPs, which have excellent temporal resolution and high sensitivity to automatic and sometimes subconscious language processes (e.g., Kaan, 2007). ERPs help to reveal processing patterns undetected by the less sensitive behavioral and offline measures used in previous studies. In the rest of this introduction, we first provide an overview of the Mandarin topic structure and the debate around its syntactic nature. We then review background literature on the processing of filler-gap dependencies, referential dependencies, island constraint observation, and relevant ERP signatures. Next, we discuss existing ERP evidence on the processing of Chinese topic structures and other filler-gap dependencies, before introducing the design and predictions of the current experiment.

\section{The Topic Structures in Mandarin Chinese}

As noted above, the term "topic structure" in Chinese generally refers to constructions sharing the following properties: there is usually a nominal phrase (the topic) at the left edge of the clause (the comment); the topic is typically definite (i.e., the book) or generic (i.e., water), and is known to parties of the conversation; and the comment usually adds new information about the topic (Shi, 2000). Unlike the other topic-prominent Asian languages such as Japanese or Korean, Chinese topic structures lack overt topic markers (Xu, 2017). While Mandarin topic constructions are usually classified into several distinct types, we will deal exclusively with the type which involves an overt gap as in sentence (1), sometimes known as the gap-type topic structure (Huang et al., 2009) $)^{2}$. The gap-type topic structure exhibits many properties of movement-derived syntactic dependencies, including allowing prepositional phrases and parts of an idiom to be a topic, showing binding reconstruction effects (Huang et al., 2009), and obeying island constraints, one of the hallmarks of syntactic movement. Consider the following two examples:

(2) $* \mathrm{Lisi}_{\mathrm{i}}$, wo renshi [henduo [[ $\mathrm{e}_{\mathrm{i}}$ xihuan] de] ren]. Lisi I know many like DE person 'Lisi $i_{i}$, I know many people who e $e_{i}$ likes.'

(3) $* \mathrm{Lisi}_{\mathrm{i}}$, zhe jian shi [gen $\mathrm{e}_{\mathrm{i}}$ mei lai] mei you Lisi this CL matter with not come not have guanxi. relation

' $L i s i_{i}$, this matter is not related to [his $\left.\mathrm{i}_{\mathrm{i}}\right]$ not having come.'

Both (2) and (3) above show that island constraints are actively observed-topics cannot be extracted out of a complex noun phrase island as in (2), or an adjunct island as in (3). However, well-known counter examples are not difficult to find. For example, in contrast to (2), a topic can be moved out of a complex noun phrase island, as illustrated in the examples below from Xu (2017):

(4)

Zhe ben $\operatorname{shu}_{\mathrm{i}} \quad\left[\left[\begin{array}{lllll}\mathrm{du} & \text { guo } \mathrm{e}_{\mathrm{i}} & \mathrm{de}\end{array}\right] \mathrm{ren}\right]$ bu duo $]$. this CL book read Asp DE people not many 'This book ${ }_{i}$, people who have read $e_{i}$ are not many.'

Furthermore, the Sentential Subject Island Constraint, the Left Branch Condition (LBC), as well as Adjunct Conditions can also be violated (Huang et al., 2009), leading some scholars to argue that if Subjacency (Chomsky, 1986) is not consistently observed, then the gap-type topic structure must be base-generated like other types of topic structures without overt gaps (e.g., Xu and Langendoen, 1985). Various pro-movement proposals have been put forward to reconcile this inconsistency in obeying island constraints, among which the Generalized Control Rule (GCR) proposed by Huang (1984) is the most well-known. Huang (1984) claims that island violations mostly occur when a given island is in a subject or pre-subject position, and that this is related to the fact that Chinese, unlike English, allows an empty pronoun (pro) in all argument positions. Huang (1984) further claims that empty pronouns are governed by GCR: Co-index an empty pronominal with the closest nominal element (Huang, 1984, p. 552 ), by which a pro can co-index with the closest NP and bypass the island constraint. Consider the following two examples from Huang et al. (2009):

(5) Lisi $_{\mathrm{i}}, \quad\left[\mathrm{e}_{\mathrm{i}}\right.$ change ge $\left.\mathrm{de}\right]$ shengyin] hen haoting. $\mathrm{Lis}_{\mathrm{i}}$, sing song $\mathrm{DE}$ voice very good 'Lisi $i_{i}$, the voice with which he $e_{i}$ sings is very good.'

${ }^{2}$ This "gap-type" topicalization may have two different word orders: OSV and SOV. They are known to be quite different (Huang et al., 2009), and the focus of this paper is the first type. 
(6)

* Lisi $_{\mathrm{i}}$ wo hen xihuan [[ $\mathrm{e}_{\mathrm{i}}$ chang ge de ] shengyin]. Lis $_{\mathrm{i}}$ I very like sing song $\mathrm{DE}^{3}$ voice. 'Lisi $i_{i}$, I like the voice with which he $\mathrm{e}_{\mathrm{i}}$ sings.'

In (5), the empty category is co-indexed with Lisi, base-generated according to GCR. In (6), however, GCR requires the empty category to be co-indexed with the closest NP wo "I." This reading is not possible, so this sentence is judged ungrammatical.

This solution, however, doesn't work when the relative clause is contained in object position, which also seems to allow extraction from islands, contrary to what Huang (1984) claims (Xu, 2017), as seen in the following sentence (7):

(7) Nei ben $\operatorname{shu}_{i}$ [wo renshi hen duo [[e $e_{j}$ kan bu that CL book I know very many read not dong $\quad e_{i}$ de $\left.\left.\operatorname{ren}_{j}\right]\right]$ understand DE people

'That book $\mathrm{i}_{\mathrm{i}}$ I know many people who cannot understand $\mathrm{e}_{\mathrm{i}}$.'

Other solutions on purely syntactic grounds are not without problems either. It has been proposed that the empty object in sentences like (7) is a so-called "zero resumptive pronoun" (Kim, 2001). Because overt pronouns don't take inanimate antecedents in Mandarin, Kim (2001) claims that the empty object must remain phonologically null in sentences like (7). However, this proposal fails to explain the optionality of resumptive pronouns when the antecedent is an animate NP, as shown by the two examples from Xu (2017): is perfectly okay to do so when the island is headed by a non-specific noun phrase. Note that Xu's (2017) observation is not unique to Mandarin Chinese. In fact, many languages-those with movement-derived topicalization included-allow topic extractions from complex noun phrase islands in some cases, in particular when existential constructions with an indefinite/nonspecific pivot or relative clause head are involved (i.e., Kush et al., 2013). An example from English via Chung and McCloskey (1983) is shown below:

\section{(11) This is a paper [ that we really need to find [someone} who understands $\left.e_{i}\right]$ ].

We see that (11) is similar to the Mandarin example (10) above in that both contain a "non-presupposititional indefinite" relative clause (Sichel, 2018) that nullifies the complex noun phrase island constraint. While different syntactic analyses have been proposed to account for sentences like (11) (e.g., Müller, 2015; Sichel, 2018), whether they apply to Mandarin Chinese topic constructions has not been studied and is beyond the scope of this paper. Since the relative clause specificity related island violations are a well-attested "exception" to island constraints for movement-induced topicalization, they are not suitable constructions to consider for the movement vs. base-generation controversy of the current Mandarin topic structure. As will be seen in the materials section, we took care to avoid relative clauses that are existential and indefinite. Furthermore, it should

(8) Zhe wei houxuanren $n_{i}$ [women zai ge di jiandao le wushu $\left[e_{j}\right.$ yonghu ta $\left.\mathrm{de}_{\mathrm{i}} \mathrm{ren}_{\mathrm{j}}\right]$ ].

8) this CL candidate we at every place saw Asp countless support him DE people 'The candidate, we saw numerous people who supported him everywhere.'

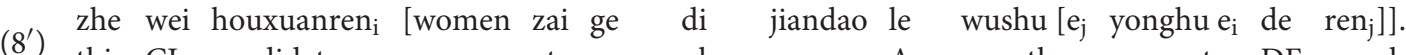
this CL candidate we at every place saw Asp countless support DE people 'The candidate, we saw numerous people who supported him everywhere.'

(8) and $\left(8^{\prime}\right)$ are identical. If resumptive pronoun is phonological suppressed when the antecedent is inanimate, it is not clear why it is also "zero" when the antecedent is animate.

Additional accounts to explain the lack of island effect involve semantic explanations to various degrees. One such account points out a contrast between specific and non-specific relativized NPs (Xu, 2017). Consider the following examples (Xu, 2017):

(9) zhe ben $s u_{i}\left[\left[\left[e_{j}\right.\right.\right.$ du guo $e_{i}$ de $\left.\left.] \operatorname{ren}_{j}\right]\right]$ bu duo. this CL book read Asp. DE person not many. 'There are not many people who read this book.' ??zhe ben $\mathrm{shu}_{\mathrm{i}}\left[\left[\left[\mathrm{e}_{\mathrm{j}} \mathrm{du}\right.\right.\right.$ guo $\left.\left.\left.\mathrm{e}_{\mathrm{i}} \mathrm{de}\right] \mathrm{ren}_{\mathrm{j}}\right]\right]$ lai le. this CL book read Asp. DE person came Asp. '??This book, the man/men who read came.'

According to $\mathrm{Xu}$ (2017), the predicate lai le "came" in (10) denotes that its subject ren "person"-the head noun of the relative clause (island) - is a specific individual. In contrast, the predicate hen duo "are many" in (9) doesn't pose specificity of its subject. While extracting an object from an island headed by a specific noun phrase is less acceptable as in (10), it

$\overline{{ }^{3} \mathrm{DE} \text { is the relative clause marker. }}$ be noted that counter examples to Xu's (2017) generalization do exist. Consider the following example (12) in contrast to (11):

na ge qianbao $i\left[\left[e_{j}\right.\right.$ zhaodao $e_{i}$ de $]$ ren $\left.\left._{j}\right]\right]$ lai le. that CL wallet found DE person came Asp. 'That wallet, the person who found it came.'

??zhe ben $\operatorname{shu}_{i}\left[\left[\left[e_{j} d u\right.\right.\right.$ guo $e_{i}$ de $\left.\left.] \operatorname{ren}_{j}\right]\right]$ lai le. this CL book read Asp. DE person came Asp. '??This book, the man/men who read came.'

(12) and (10) both use the matrix verb lai le "came," which denotes a specific relative clause noun phrase. However, it is acceptable to extract the same specific topic from the island in (12), as opposed to (11). Xu's analysis thus fails to account for some of the data, much like the other proposals presented so far. To summarize, neither the pro-movement nor the base-generation accounts can fully explain why island constraints are observed in some cases but not others. With the judgement evidence inconclusive, we now turn to related real-time parsing evidence, which often reveal incremental and more detailed processes not 
shown by offline data. We start with findings observed in filler-gap dependencies.

\section{Processing of Filler-Gap Dependencies, Referential Dependencies, and Topicalization}

A "filler-gap dependency" refers to the relationship between a dislocated sentence constituent (known as the filler) and its originating position (the gap), where the verb typically assigns a thematic role to the filler (e.g., Frazier and Clifton, 1989). This can be seen in sentences such as "The lady (filler) that the doctor treated__ (gap) yesterday for a minor cut was from England." Filler-gap dependencies have been studied extensively in the sentence processing literature. One of the most established mechanisms for parsing filler-gap dependencies is the Active Filler Strategy (Frazier and Clifton, 1989). Research has shown that immediately upon encountering a displaced item, the parser actively searches for a possible gap location-rather than waiting until the end of the sentence to initiate the search (e.g, Omaki et al., 2015). When a potential gap site turns out to not be suitable after all (Crain and Fodor, 1985; Stowe, 1986), the parser incurs processing costs as it reevaluates the situation, resulting in (e.g.) longer reading times. At the same time, the parser observes the structural requirements for syntactic movement, such as Subjacency (Chomsky, 1986) and does not posit a gap within an island (Stowe, 1986; Phillips, 2006). Consider the following sentences (Traxler and Pickering, 1996): parsing research thanks to their excellent temporal resolution and high sensitivity to automatic and sometimes subconscious language processes (e.g., Kaan, 2007). One commonly cited ERP index is the N400 component, a centro-parietal negative-going voltage shift that typically starts $250-500 \mathrm{~ms}$ post-stimulus onset and peaks around $400 \mathrm{~ms}$ post-onset (e.g., Kutas and Hillyard, 1980). The N400 is reliably linked to accessing semantic features from long-term memory, semantic incongruities, and violations associated with a verb's arguments (e.g., Kutas and Federmeier, 2011). Another common component is the P600, a positive-going voltage wave obtained $600-900 \mathrm{~ms}$ post-stimulus onset in the parietal scalp region. The $\mathrm{P} 600$ has been consistently observed for various syntactic anomalies and processing difficulties, including phrase structure violations (e.g., Hahne and Friederici, 1999), morphosyntactic violations (e.g., Friederici et al., 1996), the "reanalyze and revise" processes triggered by syntactic ambiguities (e.g., Gouvea et al., 2010), and syntactic integration costs (Fiebach et al., 2002; Felser et al., 2003; Phillips et al., 2005).

Additionally, the P600 has also been found in various nonsyntactic contexts, including thematic role reversal (e.g., Kim and Osterhout, 2005), animacy violations (Kuperberg et al., 2007), and certain strong semantic violations following an N400 (e.g., DeLong et al., 2014). Another related ERP component is the leftanterior negativity (LAN), a negative voltage shift that occurs between 300 and $500 \mathrm{~ms}$ after the onset of the violation and is obtained in an anterior scalp location, usually on the left but sometimes observed bi-laterally (e.g., Friederici et al., 1993).
a. We like the city that the author wrote_? unceasingly and with great dedication about while waiting for a contract.
b. We like the book that the author wrote_? unceasingly and with great dedication about while waiting for a contract.
c. We like the city that the author [RC who wrote_? unceasingly and with great dedication ] saw while waiting for a contract.
d. We like the book that the author [RC who wrote_? unceasingly and with great dedication] saw while waiting for a contract.
No island; implausible
No island;
plausible
Island;
implausible
Island;
plausible

(13)

Assuming the Active Filler Strategy, the parser will attempt to fill the gap after "wrote" (the first possible gap position) in both $(13 a, b)$. A reading time delay is predicted at the verb for (13a) in comparison to (13b), as it is plausible to "write a book" but not plausible to "write a city." This plausibility effect disappears in the island conditions $(13 \mathrm{c}, \mathrm{d})$ because the parser is constrained by Subjacency (Chomsky, 1986) and avoids positing gaps within an island. These predictions were verified by Traxler and Pickering (1996), demonstrating that island constraints are obeyed in realtime when processing filler-gap dependencies in English. When interpreted in relation to the syntactic nature of the relationship between the dislocated item and the subcategorizing verb, the active positing of a gap (i.e., deployment of Active Filler Strategy) and the sensitivity to islands are evidence in direct support of a movement analysis.

Filler-gap dependency processing has also been examined using ERPs, which measure electrical activity in the brain in response to specific sensory, cognitive, and motor events. ERPs have many advantages over behavioral measures for sentence
The LAN is commonly found in response to morphosyntactic violations (e.g., Molinaro et al., 2011) and has been observed at both the filler and gap positions in filler-gap dependencies, interpreted as an index of working memory cost incurred in either maintaining the filler in or retrieving it from working memory (e.g., Felser et al., 2003).

In addition to filler-gap dependencies, the ERP method has been used to examine pronominal dependencies-which is what a base-generation account would consider the relation between the topic and its co-referent (i.e., pro) to be for the current Mandarin topic structure. Among the pronominal dependencies, a cataphoric pronominal construction such as "As he $\mathrm{e}_{\mathrm{i}}$ talked to the police, $\mathrm{John}_{\mathrm{i}}$ felt more and more agitated." is similar to fillergap dependencies in that they also trigger an active mechanismantecedent search-as soon as the parser processes the pronoun. ERP studies to date have typically used a gender/number mismatch paradigm to examine online cataphoric pronoun resolution, and have obtained an anterior negativity at the illicit antecedent position (e.g., Pablos et al., 2015), reflecting 
the morphosyntactic mismatch and/or the failure to identify an antecedent. Other referential dependencies, such as "After Mary i $_{\mathrm{i}}$ worked for $9 \mathrm{~h}$ non-stop, she $\mathrm{i}_{\mathrm{i}}$ was exhausted." do not necessarily involve a forward-looking active search, but still could be considered somewhat analogous to the topic-co-referent relation by the base-generation accounts. For such well-formed referential dependencies, a LAN has been found at the co-referent pronoun position in comparison to controls with no referential dependency. This was taken to index the cognitive operations of associating a pronoun with its antecedent on which it depends for its reference (e.g., Barkley et al., 2015).

ERP findings on the processing of topicalization constructions are limited. Most notably, Felser et al. (2003) compared brain responses from different types of filler-gap dependencies (Whmovement vs. Topicalization) in German and found that both topicalization and Wh-movement elicit a LAN at the filler, interpreted as indexing working memory load incurred for filler storage (e.g., Phillips et al., 2005). Additionally, a P600 reflective of integration cost was found at the subcategorizing verb for the Wh-dependency condition, but not for the topicalization condition. To date, only one ERP study has examined the parsing of Mandarin topic structure (Yang and Tao, 2014). In this study, grammatical topic constructions such as "The table, Manager Wang kicked twice" is compared with ungrammatical counterparts such as "The table, Manager Wang kicked *Mr. Li," as well as a non-topic control condition. A multi-word Sustained Anterior Negativity or SAN typically indicative of the working memory cost to hold a filler online (e.g., Phillips et al., 2005) was obtained between the topic noun phrase and the subcategorizing verb in the main clause. Additional ERPs were also reported, including a frontal negativity at the violating noun phrase in the ungrammatical vs. grammatical condition. Although Yang and Tao (2014) claims that their findings are overall in accordance with the movement account, issues with experimental materials (e.g., the stimuli presented without context) and component interpretations (e.g., identifying a positive component occurring at $300-500 \mathrm{~ms}$ as a P600) render this conclusion unconvincing. Another set of related ERP evidence comes from research on Chinese relative clauses, which also contain an overt English-like filler-gap dependency, and have sparked debates about whether syntactic movement is involved in their derivation, much like the "gap-type" topic structure. Although the research on Chinese relative clauses mainly focuses on whether subject or object relative clauses are more costly to process (e.g., Hsiao and Gibson, 2003; Lin and Bever, 2006; Packard et al., 2010; Hsu et al., 2009), the findings to date indicate that many aspects of Chinese relative clause processing resemble movement-derived filler-gap dependencies in other languages such as English (e.g., Yang et al., 2010). In particular, multiple studies have found a larger P600 indicative of syntactic integration cost for object relatives at or next to the subcategorizing verb (e.g., Packard et al., 2010; Yang et al., 2010), mirroring ERP results previously obtained for English, German, and Japanese (e.g., Felser et al., 2003, Phillips et al., 2005; Ueno and Kluender, 2009). This processing evidence supports the movement analysis for the derivation of Chinese relative clauses and provides important considerations for the inquiry about the processing of topic structures.

\section{Island Constraints in Gap-type Topic Constructions Processing and the Current Study}

The only real-time study that tested parser sensitivity to island constraints in the processing of Mandarin topic constructions is a self-paced reading experiment conducted by Huang and Kaiser (2008). Their experimental design takes advantage of the fact that in Chinese, a topic parasitic gap is allowed in an adjunct island when the subcategorizing verb is transitive, but not allowed when the verb is a "coverb" - a class of Chinese verbs described as having grammatical properties of both a verb and a preposition (e.g, tong "be with") (Ts'ao and Cao, 1990). Following the paradigm of Phillips (2006), which also examined parser sensitivity to parasitic gaps and island constraints, Huang and Kaiser (2008) used a $2 \times 2$ factorial design manipulating plausibility (whether the topic is a plausible object of the verb within the island) and parasitic gap possibility (transitive vs. coverb). Assuming the Active Filler Strategy (Frazier and Clifton, 1989), readers were expected to construct a parasitic gap after the first verb encountered, which happens to be within the island. As the island constraint dictates that a parasitic gap is only possible with transitive verbs but not with coverbs, a plausibility effect was expected to result in a reading time delay only in the transitive condition. These predictions were largely born out, leading Huang and Kaiser (2008) to conclude that (1) the Chinese readers actively seek a potential gap after detecting a filler as an expected part of establishing a filler-gap dependency, and (2) such a dependency is sensitive to island constraints in a highly incremental way. While Huang and Kaiser (2008) provide important processing data in support of the movement analysis for the "gap-type" topic structure, the parasitic gap constructions used in the test materials are relatively rare in Mandarin Chinese. The current study addresses this issue by adopting more commonly used topic structure test materials and expands the investigation to an additional island type (complex noun phrase island). Below in Table $\mathbf{1}$ is a set of sample stimulus sentences, created following a well-tested paradigm (Traxler and Pickering, 1996) designed specifically to probe online observation of island constraints:

In this $2 \times 2$ design, the filler (topic) is a good semantic fit with the first verb "greet" in the plausible conditions, but not so in the implausible conditions. It is congruent to "greet a teacher" in $A$ and $C$, but incongruent to "greet a file" in $B$ and $D$. Following the active search mechanism (Frazier and Clifton, 1989), the parser will integrate the topic as soon as it encounters this first verb, generating a semantic mismatch effect measured as the difference in brain response to the verb in the plausible and implausible conditions. This mismatch is predicted to generate an N400 effect, typically indicative of semantic incongruity (e.g., Kutas and Federmeier, 2000). Alternatively, it may elicit a P600, which has been observed for animacy violations, as the topics in the stimulus sentences, such as "file," are inanimate and cannot receive greetings like the animate theme (e.g., Kuperberg et al., 2007). Island conditions $C$ and $D$ contain a complex noun phrase island (a relative clause), indicated by the particle SUO (Hsu, 2006) at its left boundary 
TABLE 1 | Sample Stimuli Sentences for the Current Study.

\begin{tabular}{|c|c|c|c|c|c|c|c|c|c|}
\hline \multicolumn{10}{|c|}{ Non-island Conditions: Plausible } \\
\hline 那 & 个 老师, & 人事处 的 & 小张 & 招呼 & 了 & 编辑 & & 会 & 去找。 \\
\hline nà & gè lăoshi, & rénshìchù DE & Xiǎozhāng & zhāohu ${ }^{4}$ & le & biānji & & huì & qù zhăo \\
\hline That & CL teacher & Human Resource's & Zhang Jr. & greet & Aspa & editor & & will & go look for \\
\hline \multicolumn{10}{|c|}{ 'That teacher, after Zhang Jr. from the HR Department greeted the editor, he (Zhang) will go look for.' } \\
\hline \multicolumn{10}{|c|}{ Non-island Conditions: Implausible } \\
\hline 那 & 个文件, & 人事处的 & 小张 & 招呼 & 了 & 编辑 & & 会 & 去找 \\
\hline nà & gè wénjiàn, & rénshìchù DE & Xiǎozhāng & zhāohu & le & biānji & & huì & qù zhăo \\
\hline That & CL file & Human Resource's & Zhang Jr. & greet & Asp $^{a}$ & editor & & will & go look for \\
\hline \multicolumn{10}{|c|}{ 'That file, after Zhang Jr. from the HR Department greeted the editor, he (Zhang) will go look for.' } \\
\hline \multicolumn{10}{|c|}{ Island Conditions: Plausible } \\
\hline 那 & 个 老师, & 人事处 的 & 小张 & 所 & 招呼 的 & & 编辑 & & 会去找 \\
\hline nà & gè lǎoshi, & rénshìchù DE & Xiăozhāng & SUO & zhāohu DE & & biānji & & huì qù zhăo \\
\hline That & CL teacher & Human Resource's & Zhang Jr. & SUO & greet $\mathrm{DE} \mathrm{E}^{\mathrm{b}}$ & & editor & & will go look for \\
\hline \multicolumn{10}{|c|}{ 'That teacher, the editor that Zhang Jr. from the HR Department greeted will go look for.' } \\
\hline \multicolumn{10}{|c|}{ Island Conditions: Implausible } \\
\hline 那 & 个文件, & 人事处 的 & 小张 & 所 & 招呼的 & & 编辑 & & 会去找。 \\
\hline nà & gè wénjiàn, & rénshìchù DE & Xiăozhāng & SUO & zhāohu DE & & biānji & & huì qù zhăo \\
\hline That & CL file & Human Resource's & Zhang Jr. & SUO & greet $D E^{b}$ & & editor & & will go look for \\
\hline
\end{tabular}

${ }^{a}$ Asp, aspect marker; ${ }^{b} D E$, relativizer.

(for details about how SUO in this environment predicts an object relative clause, see ERP experiment materials below). The predictions by the movement account and base-generation account, however, differ for the island conditions. It should be noted that our stimulus sentences contain islands that appear in the subject position where subjacency violations have been widely attested with judgement data (Huang et al., 2009). If the topic structure is movement-derived and processed like the English type filler-gap dependencies, the presence of an island should block the establishment of a dependency within it. Thus, the verb zhaohu "greet," which resides inside the island, will not be integrated with the topic, and the plausibility effect obtained for the non-island conditions in the form of a N400 or a semantic P600 should disappear. The base-generation account, however, predicts a different parsing profile-as the parser recognizes the topic, it will attempt to establish a referential dependency rather than a filler-gap dependency. As the parser actively searches for the co-referent of the topic, it is not constrained by Subjacency like a filler-gap dependency. Instead, it will attempt to link the first available verb (i.e., zhaohu "greet") to the topic. Under this account, we would expect to obtain the exact same plausibility effect (i.e., the N400 or P600) regardless of islandhood.

\section{METHOD}

\section{Participants}

Thirty six native speakers of Mandarin Chinese were recruited from the University of Delaware ( 9 male). Participant ages

\footnotetext{
${ }^{4}$ Zhaohu or 招呼here is used as in Zhaohu keren or 招呼客人,and is therefore translated as "greet".
}

ranged from $18-30$ with a mean age of $24.6(S D=3.6)$. One participant was left-handed, and none reported any history of language or hearing impairments. Participants were paid \$20 for their participation. All study procedures were approved by the University of Delaware Internal Review Board (IRB) and are compliant with the principles for ethical research established by the Declaration of Helsinki.

\section{Materials}

\section{Paper-and-Pencil grammaticality judgment test}

To measure readers' offline grammatical knowledge of complex NP constraint in Mandarin Chinese, a 7-point acceptability (7 being perfectly acceptable) judgment task was administered after the ERP reading task. The critical stimuli include seven ungrammatical topic constructions such as (14) below, in which the topic is extracted from a SUO relative clause (complex NP island). Another seven grammatical topic constructions were included in the task as control sentences. These control sentences are modeled after the island condition sentences used in the ERP task, such that they also each contain a SUO relative clause, but the topic is not extracted from it (see example $d$ in Table 2 below). Another 6 sentences of varying degree of acceptability were included as fillers. The participants were given detailed instruction on how to use the rating scale.

a. Context sentence:

关于 环境 保护有一些新理论。 guānyú huánjìng bǎohù you yìxiē xin lilùn 。 'there are some new theories about environmental protection' 

b. * 一个理论, [北京大学的] 专家们 所 提出__ 的] 最近]
yí gè li lùn, Běijing dàxué $\mathrm{DE}$ Zhuānjiā mén suo tíchu DE Zuìjìn
One CL theory Beijing University's experts SUO proposed DE recently
'One theory that was proposed by the experts at the Beijing University is very popular recently.' 特别 热门
Tébié rèmén
very popular

\section{ERP experiment materials}

For the ERP session, we constructed 32 sets of stimulus sentences such as those in Table 1. Since topic NPs are typically definite entities or known from context, a sentence providing background information was created for each set and was presented before each stimulus sentence. The island conditions contain a Complex NP island, or a relative clause (RC), marked by the particle SUO. As noted above in Chinese RCs are head-final, and the parser does not recognize their existence until the very end of the clause when a relativizer DE emerges. This word order poses a challenge for experimental design if island constraints are to be tested incrementally like in head-initial languages. We resolved this issue by taking advantage of the fact that a SUO relative clause is reliably cued by the particle SUO at its left boundary (Hsu, 2006). The SUO relative clause is common in modern Mandarin Chinese and typically takes the form of SUO + Transitive verb $+\mathrm{DE}$, which means "that which is verbed," or Agent + SUO + Transitive verb + DE, which means "that which the AGENT verbed." SUO is licensed only when the relativized head noun corresponds to a gap in the object position, but not the subject position (Chiu, 1995). While accounts on SUO's syntactic role differ (e.g., as a relative pronoun for the object by Ou (2007); head of a functional projection SUO P by Chiu (1995); and an A'-bound pronominal clitic by Ting (2003), they converge in that the grammatical information encoded in SUO requires a relative clause structure, and that can be used as a predictor like the English relativier who in sentence processing for a relative clause (Huang et al., 2009). Additionally, there is no evidence suggesting that the SUO construction has any unique configurations, beyond that fact that it constitutes a relative clause island, that may block the association between a potential topic and the empty category within it.

An additional set of 32 filler sentences which appear to be very similar to the target sentence were created. However, the filler sentences either do not contain topic structures, or contain topic constructions with gap positions different from that of the experimental sentences. Half of these sentences contain a SUO construction in a variety of positions to prevent the reader from guessing where the SUO construction would appear.

TABLE 2 | Sample Stimuli Set with the Context Sentence for the Current Study.

\section{The Context Sentence}

下午有位老师过来报社送份文件

xiàwǔ you wèi lăoshi guòlái bàoshè sòng fèn wénjiàn

"In the afternoon, a teacher stopped by the newspaper general office to deliver a file."

\section{Non-island Conditions: Plausible}

\begin{tabular}{|c|c|c|c|c|c|c|c|c|}
\hline 那 & 个 老师, & 人事处 的 & 小张 & 招呼 & 了 & 编辑 & 会 & 去 找 \\
\hline nà & gè lăoshi, & rénshìchù DE & Xiǎozhāng & zhāohu & le & biānji & huì & qù zhăo \\
\hline That & CL teacher & Human Resource's & Zhang Jr. & greet & $\mathrm{Asp}^{\mathrm{a}}$ & editor & will & go look for \\
\hline
\end{tabular}

'That teacher, after Zhang Jr. from the HR Department greeted the editor, he (Zhang) will go look for.'

\begin{tabular}{|c|c|c|c|c|c|c|c|c|}
\hline \multicolumn{9}{|c|}{ Non-island Conditions: Implausible } \\
\hline 那 & 个文件, & 人事处 的 & 小张 & 招呼 & 了 & 编辑 & 会 & 去找 \\
\hline nà & gè wénjiàn, & rénshìchù $D E$ & Xiǎozhāng & zhāohu & le & biānji & huì & qù zhăo \\
\hline That & CL file & Human Resource's & Zhang Jr. & greet & $A s p^{a}$ & editor & will & go look for \\
\hline
\end{tabular}

'That file, after Zhang Jr. from the HR Department greeted the editor, he (Zhang) will go look for.'

\section{Island Conditions: Plausible}

\begin{tabular}{|c|c|c|c|c|c|c|c|}
\hline 那 & 个老师, & 人事处 的 & 小张 & 所 & 招呼 的 & 编辑 & 会去找 \\
\hline nà & gè lăoshi, & rénshìchù $\mathrm{DE}$ & Xiǎozhāng & SUO & zhāohu DE & biānji & huì qù zhăo \\
\hline That & CL teacher & Human Resource's & Zhang Jr. & SUO & greet $\mathrm{DE}^{\mathrm{b}}$ & editor & will go look for \\
\hline \multicolumn{8}{|c|}{ 'That teacher, the editor that Zhang Jr. from the HR Department greeted will go look for.' } \\
\hline \multicolumn{8}{|c|}{ Island Conditions: Implausible } \\
\hline 那 & 个文件, & 人事处 的 & 小张 & 所 & 招呼 的 & 编辑 & 会去找 \\
\hline nà & gè wénjiàn, & rénshìchù $\mathrm{DE}$ & Xiǎozhāng & SUO & zhāohu DE & biānji & huì qù zhăo \\
\hline That & $C L$ file & Human Resource's & Zhang Jr. & suo & greet $\mathrm{DE}{ }^{\mathrm{b}}$ & editor & will go look for \\
\hline
\end{tabular}

${ }^{a}$ Asp, aspect marker; ${ }^{b} D E$, relativizer. 


\section{Procedure}

After giving consent, participants were fitted with an electrode net (Geodesic Hydrocel 128) and seated in a sound-attenuating booth for the duration of the experiment. Instruction on how to read the stimuli sentences and respond to the comprehension questions was given. Participants read stimulus sentences on a computer monitor placed $\sim 30$ inches from their seated position with a serial response box placed on a tray in front of them. Each trial began with a context sentence, presented on screen in its entirety, which the participant read at their own pace. When they had read the context sentence and were ready to continue, the participant pushed a button on the response box to initiate the presentation of the stimulus sentence. The stimulus sentence was presented one word at a time in light blue font on a black background with a duration of $300 \mathrm{~ms}$ and a $200 \mathrm{~ms}$ interstimulus interval (during which the screen was blank). After the stimulus sentence had concluded, a comprehension question appeared on the screen with four possible answer choices. The participant answered the comprehension question by pressing the appropriate button on the response box. After answering the comprehension question, a new trial would begin. Prior to the start of the experiment, each participant completed 8 practice trials to familiarize themselves with the procedure and the stimulus materials. Each participant completed 256 total trials (128 experimental trials and 128 filler trials). Total EEG recording time was about a half hour. After the experiment had concluded, each participant completed the pencil-and-paper grammatical judgment task.

\section{Data acquisition and pre-processing}

The experiment was programmed with E-Prime v. 2.0, and the E-Prime Extension package for Net Station was used for EEG data acquisition. The continuous EEG signal was recorded with 128 carbon fiber core/silver-coated electrodes embedded in an elastic net (Geodesic Hydrocel 128). Before data acquisition, electrode impedances were lowered to below $50 \mathrm{k} \Omega$. The continuous EEG was recorded with an analog on-line $100 \mathrm{~Hz}$ low-pass filter and digitized with a sampling rate of $250 \mathrm{~Hz}$. After acquisition, a $0.1 \mathrm{~Hz}$ high-pass filter was applied to the continuous EEG data to remove slow drifts [within the limit recommended by Tanner et al. (2015)]. The continuous EEG was segmented into $1,000 \mathrm{~ms}$ epochs time-locked to the onset of the matrix verb with a $200 \mathrm{~ms}$ pre-stimulus period. Segmented data underwent artifact correction, bad channel replacement, and baseline correction using the ERP PCA toolbox (Dien, 2010). Segmented data was baseline corrected to the mean voltage of the $200 \mathrm{~ms}$ pre-stimulus period. Subsequent processing removed eyeblink and eye movement artifacts using EEGLAB's Independent Component Analysis.

Nine participants' data was excluded from analysis because their recorded EEG data had more than 10\% bad channels. Two participants' data was excluded for excessive high amplitude noise, and one participant's data was excluded due to shorted channels. This left a total of 24 participants whose data was retained for analysis. After exclusion, the average number of good trials per participant was 109.6 (of a possible total 128). The remaining trials were averaged into four cells: Plausible
Island (average 27.2 trials per participant); Implausible Island (avg. 27.4); Plausible Non-island (avg. 27.7); Implausible Nonisland (avg. 27.4). The averaged data was then re-referenced to the average of all electrodes. A $40 \mathrm{~Hz}$ low-pass filter was applied as a final step.

\section{PCA-Constrained Derivation of Time Windows and Electrode Regions}

We utilized a Principal Components Analysis (PCA) to determine electrode regions and time windows for ERP analysis. PCA provides a more objective way of selecting time windows and regions of interest for analysis than introspection, particularly for high-density recording montages (Spencer et al., 1999, 2001; Dien and Frishkoff, 2005; Dien et al., 2007; Dien, 2010, 2012). PCA decomposes the temporal and spatial dimensions into a linear combination of a smaller set of abstract ERP factors based on covariance patterns among time points and electrode sets. In this way, the PCA can tease apart the underlying contributions of the factors to the summed scalp activity. PCA also solves the problem of temporal and spatial gradience of ERP effects by providing factor scores-weighted descriptions of the contribution of each time sample and electrode to the overall voltage.

Following Dien et al. (2007)'s recommendations for principal components analysis of ERP data, we conducted a temporal PCA followed by a spatial independent components analysis (ICA) of each temporal component. We then selected time windows and electrode regions constrained by the PCA and computed the mean voltage for the temporal/spatial region corresponding to the factor which contributed the most to the overall variance. This voltage data was then used in a $2 \times 2$ repeated measures ANOVA with the factors Islandhood (Island vs. Non-island) and Plausibility (Plausible vs. Implausible). For the input to the PCA, we used two difference waveforms (Implausible Island minus Plausible Island and Implausible Nonisland minus Plausible Non-island) to identify any main effects of plausibility in the Island and Non-island conditions. We used difference waves instead of absolute waveforms because we are interested in the brain's response to the plausibility manipulation (the experimental effect), rather than inherent brain responses to visually presented words (such as the N170). Because we predicted (and observed) very different patterns of neural responses in the two experimental conditions (Island vs. Non-island), we conducted two separate PCAs-on the two difference cells-to ensure that the experimental effect in one condition would not be erased by an opposite-polarity effect in the other condition.

\section{RESULTS}

\section{Paper-and-pencil Grammaticality Judgment Results}

As noted above, the participants completed a grammaticality judgment task after the conclusion of the ERP session. Figure 1 shows the distribution of judgments for grammatical and ungrammatical sentences. Grammatical sentences had a mean 


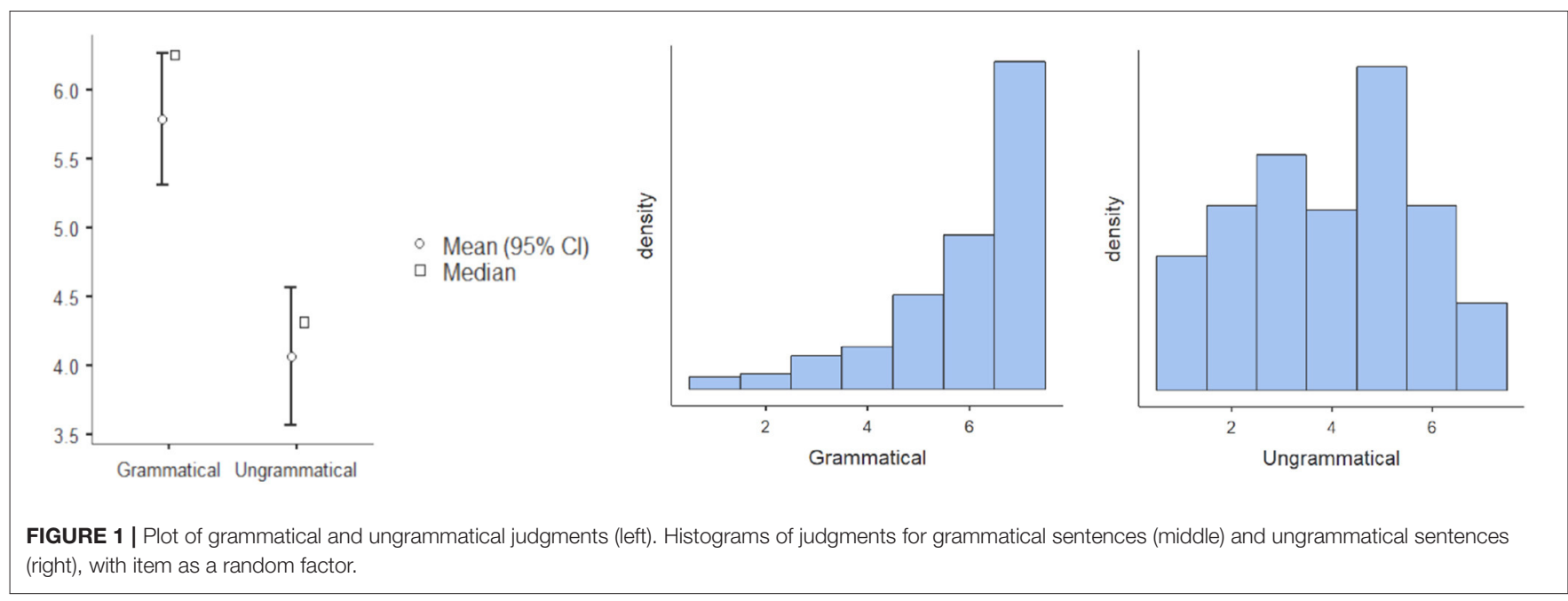

rating of $5.79(S D=1.19)$, while ungrammatical sentences had a mean rating of $4.06(S D=1.24)$. A pairwise $t$-test found a significant difference between grammatical and ungrammatical $[t(23)=8.14, p<0.001]$, confirming that they have the appropriate grammatical knowledge about island constraints in offline settings.

\section{Comprehension Question Accuracy}

During the ERP session, participants answered a comprehension question after each trial. We measured the accuracy of responses to the comprehension question to ensure that participants read and understood the stimulus sentences. Mean accuracy in the Implausible Island condition was .72 $(S D=0.098)$, in the Plausible Island condition .79 (SD $=0.109)$, in the Implausible Non-island condition .68 (SD $=0.1$ ), and in the Plausible Non-island condition .68 (SD $=0.103$ ).

\section{ERP Results}

Mean voltage data was extracted from two spatial regions of interest (ROI) defined by the selected temporospatial factor from the principal components analysis (TF01SF1-Island PCA; TF01SF1-Non-island PCA) over a time window defined with a 0.6 beta weight criterion (further details can be found in the supplemental materials). This gave a frontal ROI with a time window of 588-792 ms for the Island PCA (Figure 2) and a posterior ROI (Figure 3) with a time window of $612-796 \mathrm{~ms}$ for the Non-island PCA. These effects appear-from visual inspection of the waveforms - to begin much earlier than the specified time windows. However, the effects are not significant in earlier time windows, so we will only report the effects in the time windows specified by the PCA. Animated 3D topoplots showing the frontal and posterior effects at $732 \mathrm{~ms}$ were provided in Figure 4.

To verify statistical significance, mean voltage data was extracted from a frontal ROI over a 588-792 ms time window, both of which were defined by the Island condition PCA (TF01SF1). Figure 5 shows the mean voltage by condition in the ROI averaged over the time window. A $2 \times 2$ repeated measures ANOVA found no significant main effect of Islandhood $\left[F_{(23)}=0.59 ; p>0.05\right]$ or Plausibility $\left[F_{(23)}=1.09 ; p>0.05\right]$, but a significant Islandhood $\times$ Plausibility interaction $\left[F_{(23)}=\right.$ 4.84; $p=0.038$ ]. Planned $t$-tests found a significant difference between Implausible and Plausible in the Island condition $[t(24)$ $=2.2 ; p=0.038$ ] but no significant difference in the Non-island condition $[t(24)=0.369 ; p>0.05]$, verifying that the frontal positivity is present only in the island conditions. Additional linear regression analysis found no significant correlations between voltage in either the Island or Non-island conditions and comprehension question accuracy or grammaticality judgments ${ }^{5}$ (all $p>0.05$ ).

For the posterior region, mean voltage data was also extracted from a posterior region of interest over a 612$796 \mathrm{~ms}$ time window defined by the Non-island condition PCA (TF01SF1). Figure 6 shows the mean voltage by condition in the ROI averaged over the time window. A $2 \times 2$ repeated measures ANOVA found a significant main effect of Islandhood $\left[F_{(23)}=12.23 ; p=0.002\right]$ but no significant main effect of Plausibility $\left[F_{(23)}=0.413 ; p>0.05\right]$. Additionally, there was a significant Islandhood $\times$ Plausibility interaction $\left[F_{(23)}=11.14 ; p\right.$ $=0.005]$. Planned $t$-tests found a significant difference between Implausible and Plausible in both the Island condition $[t(24)$ $=2.28 ; p=0.032]$ and Non-island condition $[t(24)=2.21 ; p$ $=0.026]$. Linear regressions found no significant correlations between voltage in either the Island or Non-island conditions and comprehension question accuracy or grammaticality judgments $(p>0.05)$.

\footnotetext{
${ }^{5}$ Grammaticality judgment "polarity" was calculated by first calculating zscores for grammatical and ungrammatical sentences for each participant, and then taking the difference between these $\mathrm{z}$-scores. This score represents how divergent the judgments were for grammatical and ungrammatical sentences for each participant. Participants with a high polarity score gave higher than average ratings to grammatical sentences and lower than average ratings to ungrammatical sentences. Participants with a low polarity score gave lower than average ratings to grammatical sentences and higher than average ratings to ungrammatical sentences.
} 


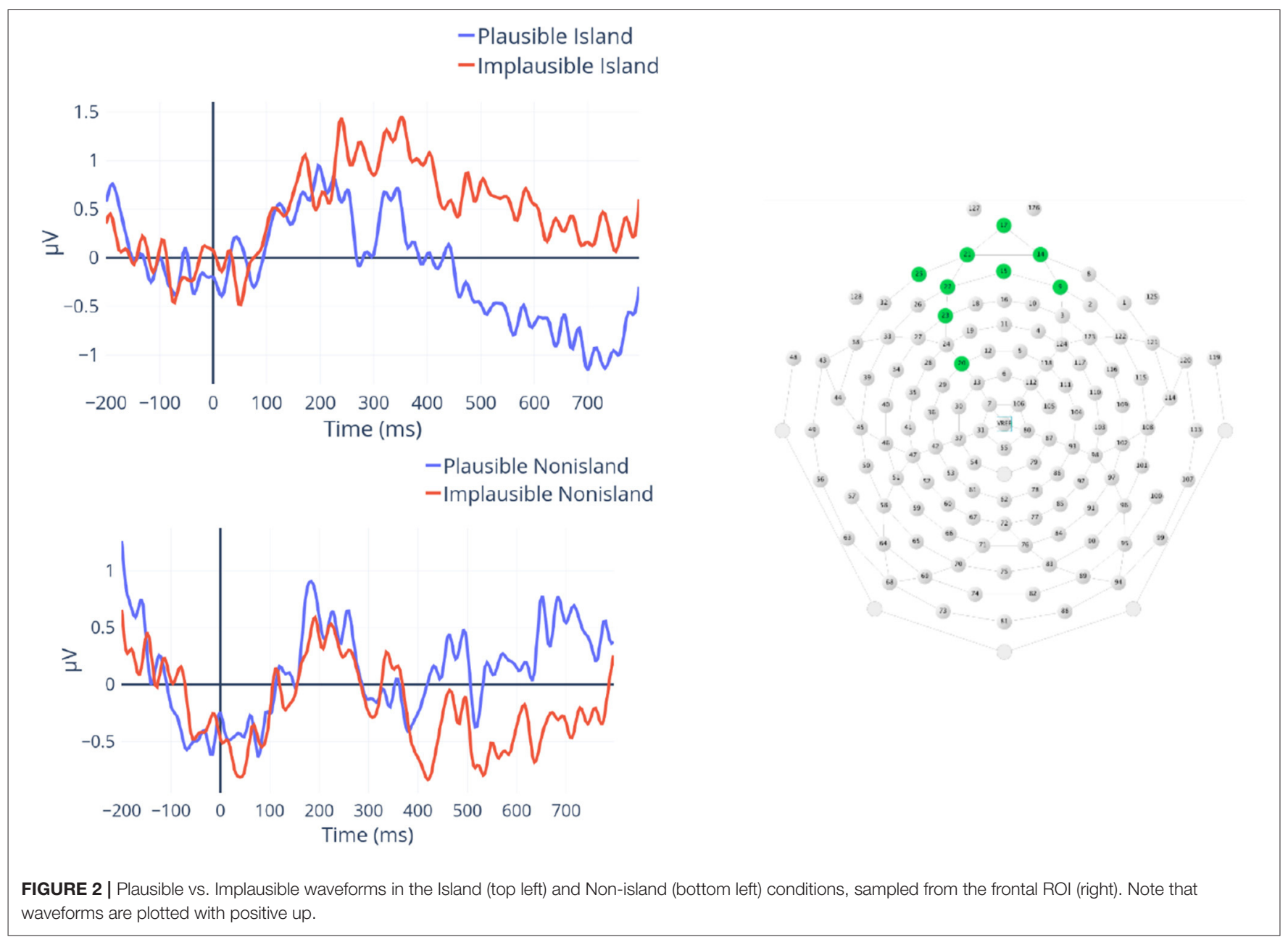

\section{DISCUSSION}

In this study we measured ERPs to determine how the gaptype Mandarin topic construction is processed in real time. We followed the paradigm of Traxler and Pickering (1996) and adopted a novel experimental design in which an upcoming complex noun phrase island could be predicted by the particle SUO, which marks the left boundary of an object relative clause. By testing whether the island constraint is obeyed online, we hope to elucidate whether the gap-type topic structure is derived via syntactic movement and forms a filler-gap dependency like the English-type topicalization. Although we did not obtain the expected N400 effect in response to the plausibility manipulation, we did observe a posterior positivity $612-796 \mathrm{~ms}$ after the first verb in the implausible ("greet the file") relative to the plausible ("greet the teacher") non-island conditions, suggesting that the parser actively searches for a potential verb to resolve the dependency as the sentence unfolds. Considering the time course and scalp distribution of this positivity, we interpret it as a P600 indicative of the predicted plausibility effect, as "greet a file" in the implausible condition creates an animacy violation in comparison to "greet a teacher" in the plausible condition.
Note that the P600 has been reliably found for animacy violations in previous literature (e.g., Kuperberg et al., 2007). Importantly, we see that this P600 disappeared in the island conditions, suggesting that the topic was not linked to the verb inside the island. Such a result is consistent with the predictions of the movement accounts but not with the base-generation accounts. Additionally, we found a fronto-central positivity occurring from 588 to $792 \mathrm{~ms}$ at the verb within the SUO island, such as that implausible island condition is more positive than the plausible island condition. In our attempt to investigate the nature of this novel ERP, we first considered the so-called anterior Post-N400-Positivity (aPNP), which typically occurs anywhere from 300-1,000 ms at frontal sites (e.g., Thornhill and Van Petten, 2012; DeLong et al., 2014). However, the aPNP is evoked in a very different experimental manipulation, namely, for a plausible but contextually unexpected word, such as the "mistake" relative to the control "splash" in "Bill jumped in the lake. He made a big? mistake/splash with his cannonball” (e.g., DeLong and Kutas, 2020). Importantly, aPNP has always been obtained after an N400, which is absent in our findings. Another possibility is that the current ERP is a frontally distributed P600 (fP600), sometimes obtained for syntactic ambiguity and 

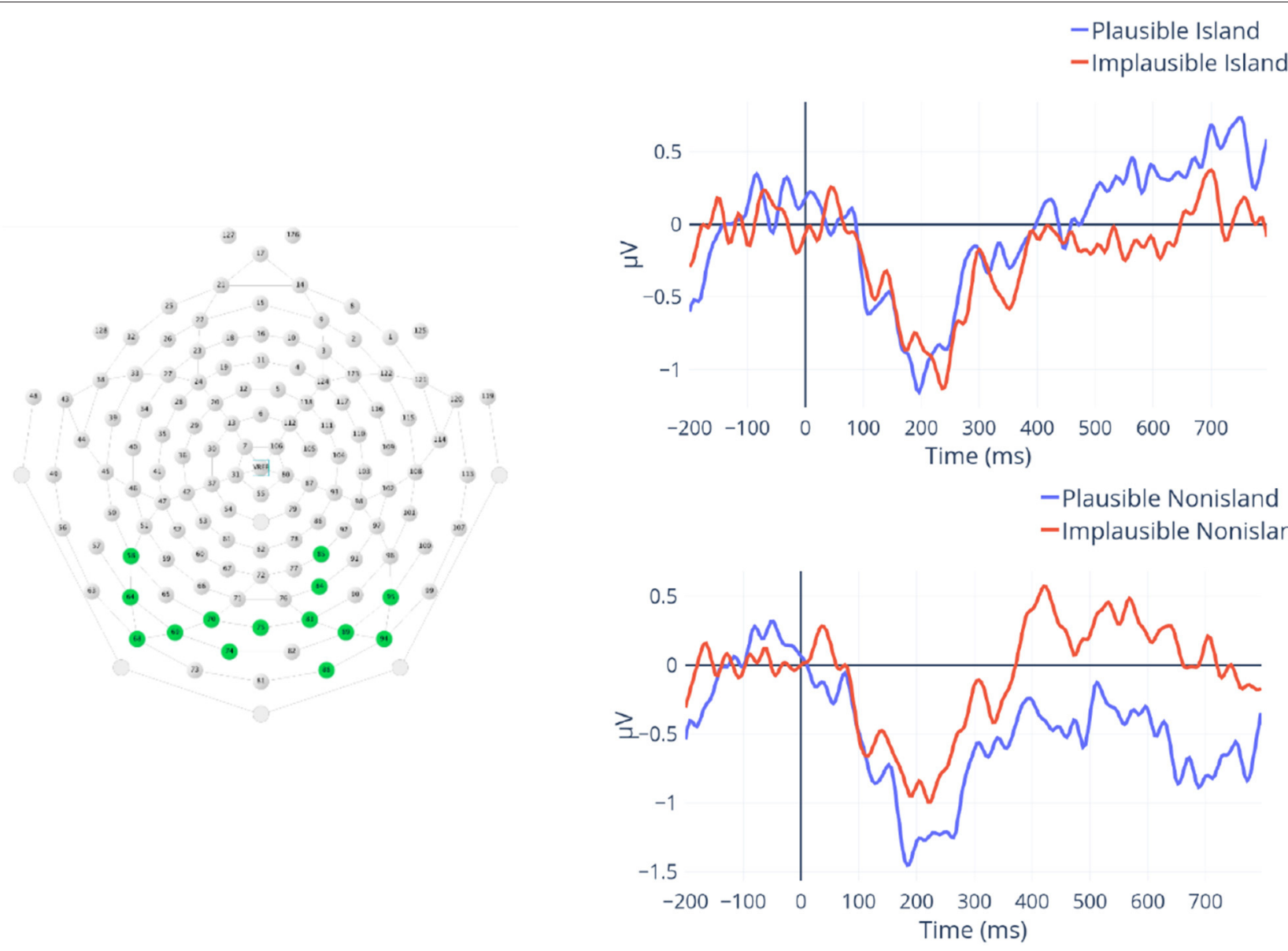

FIGURE 3 | Plausible vs. Implausible waveforms in the Island (top) and Non-island (bottom) conditions, sampled from the posterior ROI (left panel).

discourse complexity (e.g., Kaan and Swaab, 2003). However, the fP600 was usually found in more central regions with broader scalp distributions (e.g., Friederici et al., 2002) rather than in a concentrated fronto-central site like our observed effect. Further, while both island conditions are complex constructions with a relative clause and three noun phrases, the implausible condition is not necessarily more complex than the plausible condition to induce an fP600. In fact, as the implausible island condition contains only two Agent noun phrases and one Theme noun phrase, in comparison to the three Agent noun phrases in the plausible island condition-it has less discourse complexity and less syntactic ambiguity. It remains unclear how to interpret the fronto-central positivity we obtained, and future research is clearly warranted to examine this component further.

While the process underlying the observed fronto-central positivity is yet to be determined, we maintain that our findings suggest that the parser avoided establishing a gap within an island upon recognizing its left boundary marked by the SUO particle, as the island vs. non-island conditions yielded qualitatively different ERPs. As stated clearly in the predictions earlier, if the topic is linked to the potential subcategorizing verb in a referential dependency in line with the based-generation account, we should have found the same component (i.e., the semantic P600) indicative of a plausibility effect for the non-island conditions. However, the observed frontal positivity is unlikely to reflect such a plausibility effect, as the "semantic P600" has never been found in the anterior regions (e.g., Kim and Osterhout, 2005; Kuperberg et al., 2007; DeLong et al., 2014). The frontal positivity is also not the expected ERP to reflect cost associated with referential dependency resolution which typically generates a LAN instead (e.g., Barkley et al., 2015; Pablos et al., 2015). Similarly, the frontal positivity is unlikely to indicate filler integration cost incurred at a potential gap site either as discovered by previous filler-gap dependency studies (e.g., Felser et al., 2003). In these studies, particularly those examining the processing of Chinese relative clauses, such integration costs elicited a posterior P600 rather an anterior late positivity (e.g., Packard et al., 2010; Yang et al., 2010). These considerations render it difficult to link the frontal positivity to any kind of dependency previously reported in the literature. We conclude that the on-line parsing of the "gap-type" topic construction obeys the subjacency condition (Chomsky, 1986), much like the filler-gap dependencies formed via syntactic movement.

In addition to the ERP experiment, we conducted a grammaticality judgment task to verify knowledge about the 


\section{Island - TF01 (732 ms)}

\section{Nonisland - TF01 (732 ms)}
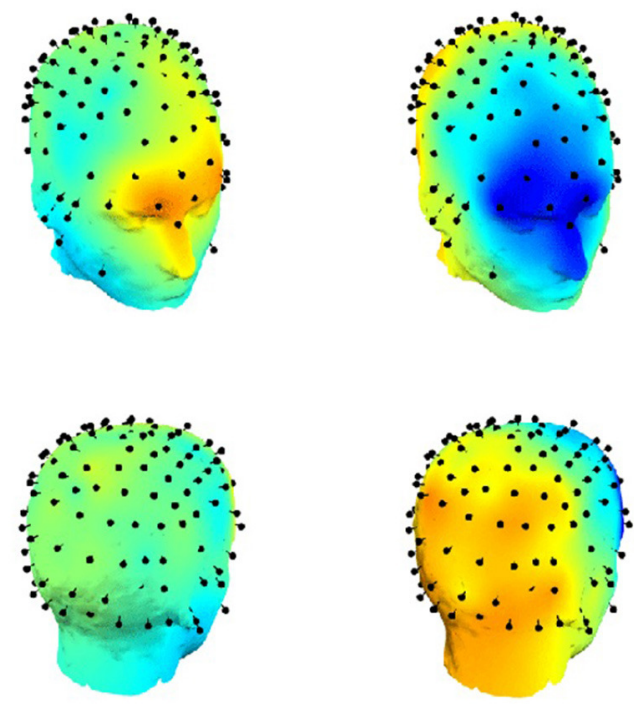

FIGURE 4 | Topoplots showing the frontal and posterior effects at $732 \mathrm{~ms}$ in the Island condition (Left) and Non-island condition (right). For animated 3D topoplot, please see Supplementary Video 1 in the Supplementary Materials.

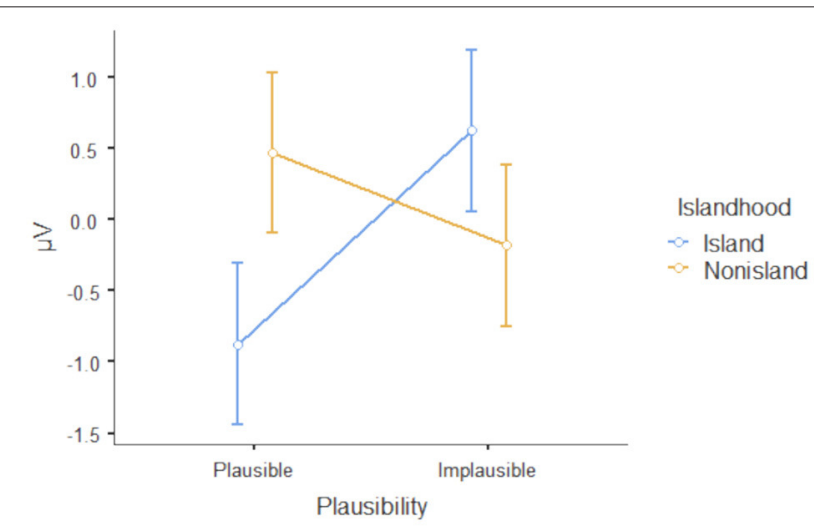

FIGURE 5 | Mean voltage by condition in the frontal ROI. Bars represent standard error.

restrictions imposed on long-distance dependencies. Results reveal that the participants rated sentences in which topics were extracted from a SUO complex NP island significantly less acceptable than the control sentences, confirming that they have the appropriate grammatical knowledge about island constraints in offline settings. The judgment data also verifies the validity of using SUO as a predictor for an upcoming object relative clause (i.e., complex noun phrase island) in the test materials. During the ERP session, online reading comprehension accuracy were also collected. These findings show that the overall comprehension accuracy rate for the questions was $71 \%$. Although this rate may appear low, it is

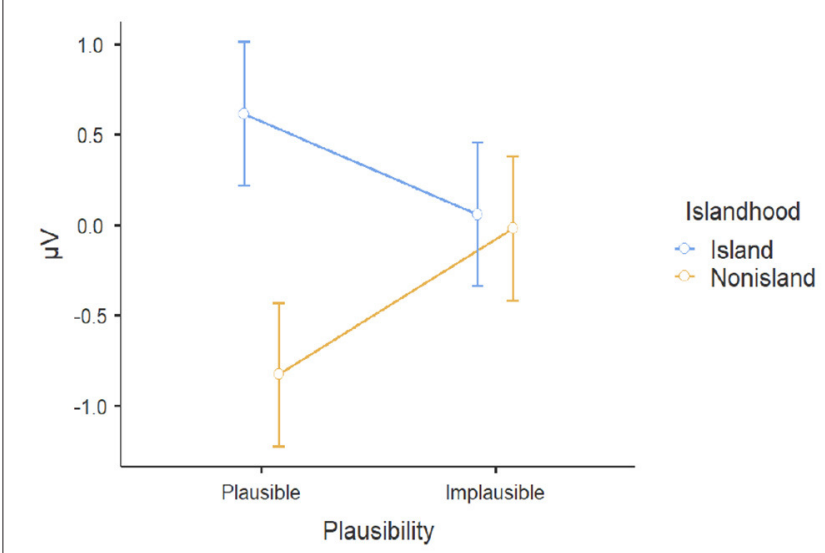

FIGURE 6 | Mean voltage by condition in the posterior ROI.

expected due to the high structural and discourse complexity of the stimulus sentences. As shown in Table 2 Materials section above, each stimulus sentence includes a background story, three separate noun phrases, and multiple events. In order to answer the comprehension question accurately, the reader must keep track of all events described in the sentence and maintain the information in memory. Additionally, it is important to note that full global comprehension may not be necessary for a human parser to apply certain highly automatic grammatical constraints such as the subjacency requirement. When examining the comprehension question accuracy rate by condition, we see that comprehension questions for the island conditions were more accurately answered than the non-island conditions. This can be explained if the parser skips the island entirely upon encountering SUO, rather than attempting to construct a gap at an inappropriate site and then having to reanalyze-a process which occurs in the non-island conditions. Consequently, the parser could attend to the events depicted in the sentence better and retain the information in memory for a longer time.

While our findings are compatible with the movement analysis, it is important to note that we only tested one kind of island constraint, namely the complex noun phrase constraint, and with only one type of relative clause (object relative clause appeared in the subject position in the main clause). This is mostly because Chinese relative clauses are head-final, rendering it difficult for the parser to recognize the left boundary and to activate island constraints incrementally without a particular design like ours. However, future research can explore additional designs in order to test the parsing of other island constraints in topic structures. Additionally, and as mentioned before, semantic-related factors, in particular the type of relative clause involved, seem to affect whether island constraints are obeyed for topicalization in not only Mandarin Chinese but also many other languages. To shed light on this issue, future Chinese topic research can also examine the processing of relative clause island that are existential and with 
specific heads, perhaps with a different paradigm that can make this possible.

To conclude, this study contributes new neurophysiological evidence to the understanding of Chinese topic constructions, an understudied area in Chinese sentence processing research. Our findings demonstrate that during the online processing of the gap-type topic construction-a common type of Chinese topicalization-the parser actively searches for a suitable gap as soon as it encounters a dislocated topic. This processing pattern has been consistently found for fillergap dependencies derived from syntactic movement in many languages. Additionally, our ERP results reveal a sensitivity to island constraints in the real-time parsing of the gaptype topic structure, and thus contribute processing evidence in direct support of the movement analysis of Chinese topic structures.

\section{DATA AVAILABILITY STATEMENT}

The raw data supporting the conclusions of this article will be made available by the authors, without undue reservation. Raw data of the current study is accessible at https://osf.io/7p6ky/? view_only=c43600fae31a41d99ce0a624d15a63df.

\section{REFERENCES}

Barkley, C., Kluender, R., and Kutas, M. (2015). Referential processing in the human brain: an event-related potential (ERP) study. Brain Res. 1629, 143-159. doi: 10.1016/j.brainres.2015.09.017

Ben-Shachar, M., Palti, D., and Grodzinsky, Y. (2004). Neural correlates of syntactic movement: converging evidence from two fMRI experiments. Neuroimage 21, 1320-1336. doi: 10.1016/j.neuroimage.2003.11.027

Chiu, B. (1995). An object clitic projection in Mandarin Chinese. J. East Asian Linguist. 4, 77-117. doi: 10.1007/BF01731613

Chomsky, N. (1986). Barriers, Vol. 13. Cambridge, MA: MIT press.

Chung, S., and McCloskey, J. (1983). On the interpretation of certain island facts in GPSG. Linguist. Inq. 14, 704-713.

Crain, S, and Fodor, J (1985). "How can grammar help parsers?" in Natural Language Parsing: Psycholinguistics, Computational, and Theoretical Perspectives, eds D. Dowty, L. Karttunen, and A. M. Zwicky (Cambridge: Cambridge University Press), 94-128. doi: 10.1017/CBO9780511597855.004

DeLong, K. A., and Kutas, M. (2020). Comprehending surprising sentences: sensitivity of post-N400 positivities to contextual congruity and semantic relatedness. Langu. Cogn. Neurosci. 35, 1-20. doi: 10.1080/23273798.2019.1708960

DeLong, K. A., Quante, L., and Kutas, M. (2014). Predictability, plausibility, and two late ERP positivities during written sentence comprehension. Neuropsychologia 61, 150-162. doi: 10.1016/j.neuropsychologia.2014.06.016

Dien, J. (2010). The ERP PCA Toolkit: An open-source program for advanced statistical analysis of event-related potential data. J. Neurosci. Methods 187, 138-145. doi: 10.1016/j.jneumeth.2009.12.009

Dien, J. (2012). Applying principal components analysis to eventrelated potentials: a tutorial. Dev. Neuropsychol. 37, 497-517. doi: 10.1080/87565641.2012.697503

Dien, J., and Frishkoff, G. A. (2005). "Introduction to principal components analysis of event-related potentials," in Event-Related Potentials: A Methods Handbook, ed T. Handy (Cambridge, MA: MIT Press), 189-208.

Dien, J., Khoe, W., and Mangun, G. R. (2007). Evaluation of PCA and ICA of simulated ERPs: Promax vs. infomax rotations. Hum. Brain Mapp. 28, 742-763. doi: 10.1002/hbm.20304

\section{ETHICS STATEMENT}

The studies involving human participants were reviewed and approved by University of Delaware Research Compliance and Ethics Program. The patients/participants provided their written informed consent to participate in this study.

\section{AUTHOR CONTRIBUTIONS}

ZD: conceptualization, methodology, formal analysis, investigation, and writing-original draft. RR: methodology, formal analysis, investigation, writing-method section, review, and editing. AH: conceptualization and methodology. All authors contributed to the article and approved the submitted version.

\section{SUPPLEMENTARY MATERIAL}

The Supplementary Material for this article can be found online at: https://www.frontiersin.org/articles/10.3389/fcomm. 2021.650659/full\#supplementary-material

Supplementary Video 1 | Animated 3D topoplots showing the frontal and posterior effects at $732 \mathrm{~ms}$ in the Island condition (Left) and Non-island condition (right).

Felser, C., Clahsen, H., and Münte, T. F. (2003). Storage and integration in the processing of filler gap dependencies: An ERP study of topicalization and wh-movement in German. Brain Lang. 87, 345-354. doi: 10.1016/S0093-934X(03)00135-4

Fiebach, C. J., Schlesewsky, M., and Friederici, A. D. (2002). Separating syntactic memory costs and syntactic integration costs during parsing: the processing of German wh-questions. J. Mem. Lang. 47, 250-272. doi: 10.1016/S0749-596X(02)00004-9

Frazier, L., and Clifton, C. Jr. (1989). Successive cyclicity in the grammar and the parser. Lang. Cogn. Proces. 4, 93-126. doi: 10.1080/01690968908406359

Friederici, A. D., Hahne, A., and Mecklinger, A. (1996). Temporal structure of syntactic parsing: early and late event-related brain potential effects. J. Exp. Psychol. Learn. Mem. Cogn. 22:1219. doi: 10.1037/0278-7393.22.5.1219

Friederici, A. D., Hahne, A., and Saddy, D. (2002). Distinct neurophysiological patterns reflecting aspects of syntactic complexity and syntactic repair. $J$. Psycholinguist. Res. 31, 45-63. doi: 10.1023/A:1014376204525

Friederici, A. D., Pfeifer, E., and Hahne, A. (1993). Event-related brain potentials during natural speech processing: effects of semantic, morphological and syntactic violations. Cogn. Brain Res. 1, 183-192. doi: 10.1016/0926-6410(93)90026-2

Gouvea, A., Phillips, C., Kazanina, N., and Poeppel, D. (2010). The linguistic processes underlying the P600. Lang. Cogn. Proces. 25, 149-188. doi: 10.1080/01690960902965951

Hahne, A., and Friederici, A. D. (1999). Electrophysiological evidence for two steps in syntactic analysis: early automatic and late controlled processes. J. Cogn. Neurosci. 11, 194-205. doi: 10.1162/0898929995 63328

Hsiao, F., and Gibson, E. (2003). Processing relative clauses in Chinese. Cognition 3, 3-27. doi: 10.1016/S0010-0277(03)00124-0

Hsu, C. C. N. (2006). Issues in Head-Final Relative Clauses in Chinese: Derivation, Processing, and Acquisition. Newark, DE: University of Delaware.

Hsu, C. C. N., Hermon, G., and Zukowski, A. (2009). Young children's production of head-final relative clauses: Elicited production data from Chinese children. J. East Asian Linguist. 18:323. doi: 10.1007/s10831-009-9047-y

Huang, C. T. J. (1984). On the distribution and reference of empty pronouns. Linguist. Inq. 531-574.

Huang, C. T. J., Li, A., and Li, Y. F. (2009). Syntax of Chinese. Cambridge: Cambridge University Press. doi: 10.1017/CBO9781139166935 
Huang, Y. C., and Kaiser, E. (2008). "Investigating filler-gap dependencies in Chinese topicalization," in Proceedings of the 20th North American conference on Chinese linguistics, Vol. 2, (Columbus, OH), 927.

Kaan, E. (2007). Event-related potentials and language processing: a brief overview. Lang. Linguist. Compass 1, 571-591. doi: 10.1111/j.1749-818X.2007.00037.x

Kaan, E., and Swaab, T. Y. (2003). Repair, revision, and complexity in syntactic analysis: an electrophysiological differentiation. J. Cogn. Neurosci. 15, 98-110. doi: $10.1162 / 089892903321107855$

Kim, A., and Osterhout, L. (2005). The independence of combinatory semantic processing: Evidence from event-related potentials. J. Mem. Lang. 52, 205-225. doi: 10.1016/j.jml.2004.10.002

Kim, S. (2001). Chain composition and uniformity. Nat. Lang. Linguist. Theory 19, 67-107. doi: 10.1023/A:1006482613603

Kuperberg, G. R., Kreher, D. A., Sitnikova, T., Caplan, D. N., and Holcomb, P. J. (2007). The role of animacy and thematic relationships in processing active English sentences: evidence from event-related potentials. Brain Lang. 100, 223-237. doi: 10.1016/j.bandl.2005.12.006

Kush, D., Omaki, A., and Hornstein, N. (2013). "11 Microvariation in islands?" in Experimental Syntax and Island Effects, eds J. Sprouse and N. Hornstein (Cambridge: Cambridge University Press), 239.

Kutas, M., and Federmeier, K. D. (2000). Electrophysiology reveals semantic memory use in language comprehension. Trends Cogn. Sci. 4, 463-470. doi: 10.1016/S1364-6613(00)01560-6

Kutas, M., and Federmeier, K. D. (2011). Thirty years and counting: finding meaning in the $\mathrm{N} 400$ component of the eventrelated brain potential (ERP). Annu. Rev. Psychol. 62, 621-647. doi: 10.1146/annurev.psych.093008.131123

Kutas, M., and Hillyard, S. A. (1980). Event-related brain potentials to semantically inappropriate and surprisingly large words. Biol. Psychol. 11, 99-116. doi: 10.1016/0301-0511(80)90046-0

Li, C.N. (1976). "Subject and topic: a new typology of language," in Subject and Topic, ed Charles N (New York, NY: Academic Press), 458-489.

Li, C. N., and Thompson, S.A. (1981). Mandarin Chinese: A Functional Reference Grammar, Vol.3. Oakland, CA: University of California Press.

Lin, C. J. C., and Bever, T. G. (2006). "Subject preference in the processing of relative clauses in Chinese," in Proceedings of the 25th west coast conference on formal linguistics, Vol. 25 (Somerville, MA: Cascadilla Proceedings Project), 254-260.

Molinaro, N., Barber, H. A., and Carreiras, M. (2011). Grammatical agreement processing in reading: ERP findings and future directions. Cortex 47, 908-930. doi: 10.1016/j.cortex.2011.02.019

Müller, C. (2015). Against the small clause hypothesis: evidence from swedish relative clause extractions. Nordic J. Linguist. 38:67. doi: $10.1017 /$ S0332586515000062

Ning, C. (1993). The Overt Syntax of Relativization and Topicalization (Doctoral dissertation). Irvine, CA: University of California Irvine.

Omaki, A., Lau, E. F., Davidson White, I., Dakan, M. L., Apple, A., and Phillips, C. (2015). Hyper-active gap filling. Front. Psychol. 6:384. doi: $10.3389 /$ fpsyg. 2015.00384

$\mathrm{Ou}$, T. S. (2007). Suo relative clauses in Mandarin Chinese. Language and Linguistics, 8, 913-937.

Pablos, L., Doetjes, J., Ruijgrok, B., and Cheng, L. L. S. (2015). Active search for antecedents in cataphoric pronoun resolution. Front. Psychol. 6:1638. doi: $10.3389 /$ fpsyg. 2015.01638

Packard, J. L., Ye, Z., and Zhou, X. (2010). "Filler-gap processing in Mandarin relative clauses: Evidence from event-related potentials," In Processing and Producing Head-Final Structures (Dordrecht: Springer), 219-240. doi: 10.1007/978-90-481-9213-7_11
Phillips, C., Kazanina,. N., and Abada,. S. H. (2005). ERP effects of the processing of syntactic long- distance dependencies. Cogn. Brain Res. 22, 407-428. doi: 10.1016/j.cogbrainres.2004.09.012

Phillips,. C. (2006). The real-time status of island phenomena. Language 82, 4, 795-823. doi: 10.1353/lan.2006.0217

Shi, D. (2000). Topic and topic-comment constructions in Mandarin Chinese. Language 76, 383-408. doi: 10.1353/lan.2000.0070

Shyu, S. (1995). The Syntax of Focus and Topic in Mandarin Chinese (Doctoral dissertation). Los Angeles, CA: University of Southern California.

Sichel, I. (2018). Anatomy of a counterexample: Extraction from relative clauses. Linguist. Inq. 49, 335-378. doi: 10.1162/LING_a_00275

Spencer, K. M., Dien, J., and Donchin, E. (1999). A componential analysis of the ERP elicited by novel events using a dense electrode array. Psychophysiology 36, 409-414. . doi: 10.1017/S0048577299981180

Spencer, K. M., Dien, J., and Donchin, E. (2001). Spatiotemporal analysis of the late ERP to deviant stimuli.pdf. Psychophysiology 38, 343-358. . doi: 10.1111/1469-8986.3820343

Stowe, L. A. (1986). Evidence for on-line gap location. Langu. Cogn. Process. 1, 227-245. . doi: 10.1080/01690968608407062

Tanner, D., Morgan-short, K., and Luck, S. J. (2015). How inappropriate highpass filters can produce artifactual effects and incorrect conclusions in ERP studies of language and cognition. Psychophysiology 52, 997-1009. . doi: $10.1111 /$ psyp. 12437

Thornhill, D. E., and Van Petten, C. (2012). Lexical versus conceptual anticipation during sentence processing: frontal positivity and N400 ERP components. Int. J. Psychophysiol. 83, 382-392. doi: 10.1016/j.ijpsycho.2011.12.007

Ting, J. (2003). The nature of the particle suo in Mandarin Chinese. J. East Asian Linguist. 12, 121-139. doi: 10.1023/A:1022463417943

Traxler, M. J., and Pickering, M. J. (1996). Plausibility and the processing of unbounded dependencies: an eye-tracking study. J. Mem. Lang. 35, 454-475. doi: 10.1006/jmla.1996.0025

Ts'ao, F. F., and Cao, F. (1990). Sentence and Clause Structure in Chinese: A Functional Perspective. Taipei, ROC: Student Book Co., Ltd.

Ueno, M., and Kluender, R. (2009). On the processing of Japanese whquestions: an ERP study. Brain Res. 1290, 63-90. doi: 10.1016/j.brainres.2009. 05.084

$\mathrm{Xu}$, L. (2017). “Topicalization in Asian languages,"in The Wiley Blackwell Companion to Syntax, Second Edition, eds M. Everaert and H. C. Riemsdijk (Hoboken, NJ: John Wiley \& Sons), 1-30. doi: 10.1002/9781118358733.wbsyncom024

Xu, L., and Langendoen,. D. T. (1985). Topic Structures in Chinese. Language 61, 1-27. doi: $10.2307 / 413419$

Yang, C. L., Perfetti, C. A., and Liu, Y. (2010). Sentence integration processes: An ERP study of Chinese sentence comprehension with relative clauses. Brain Lang. 112, 85-100. doi: 10.1016/j.bandl.2009.10.005

Yang, Y., and Tao, L. (2014). Neural mechanisms of trace in Chinese topicalized constructions. Soc. Sci. China 35, 86-111. doi: 10.1080/02529203.2013.875661

Conflict of Interest: The authors declare that the research was conducted in the absence of any commercial or financial relationships that could be construed as a potential conflict of interest.

Copyright (c) 2021 Dong, Rhodes and Hestvik. This is an open-access article distributed under the terms of the Creative Commons Attribution License (CC BY). The use, distribution or reproduction in other forums is permitted, provided the original author(s) and the copyright owner(s) are credited and that the original publication in this journal is cited, in accordance with accepted academic practice. No use, distribution or reproduction is permitted which does not comply with these terms. 